\title{
A FEM Study of Molecular Transport Through a Single Nanopore in a Spherical Cell
}

\author{
Debarshi Ghosh $^{1}$ (D), Nitin Kumar Saluja ${ }^{1}$, Thakur Gurjeet Singh 2,* (D) \\ 1 Chitkara University Institute of Engineering \& Technology, Chitkara University, Punjab, India; \\ debarshi.ghosh@chitkara.edu.in (D.G.); nitin.saluja@chitkara.edu.in (N.K.S.); \\ 2 College of Pharmacy, Chitkara University, Punjab, 140401, India; gurjeet.singh@ chitkara.edu.in (T.G.S.); \\ * Correspondance: gurjeet.singh@chitkara.edu.in; gurjeetthakur@gmail.com (T.G.S.);
}

Scopus Author ID: 27667828700

Received: 9.06.2021; Revised: 12.07.2021; Accepted: 18.07.2021; Published: 8.08.2021

\begin{abstract}
Electroporation has a specific application in the delivery of drugs into the cells. In addition, the challenge is to be able to deliver the drugs effectively. The key to the electroporation-based delivery method is regulated induced transmembrane voltage (ITMV). Recently, with the advent of COVID-19, there has been an increase in clinical trials on the delivery of DNA plasmids by electroporation. As a result, the substantial number of laboratory experiments are not feasible, thereby increasing the dependency on simulation-based research. Simulations of delivery of extracellular material into the cell depend upon molecular transport modeling in an electroporated cell. In this paper, molecular transport through a single nanopore is being studied theoretically. The closed-form expression of molecular transport is used in COMSOL Multiphysics simulation to obtain extracellular concentration variation as a function of time. Sinusoidal pulses with the varying magnitude of electric field $(8 \mathrm{kV} / \mathrm{cm}$ and 10 $\mathrm{kV} / \mathrm{cm}$ ) and time duration were used to understand pulse parameters' effect on molecular transport. The simulation results match the empirical result from the literature hence validate the simulation study.
\end{abstract}

Keywords: Electroporation, Molecular Transport, Pulsed Electric Field, Cellular Electroporation

(c) 2021 by the authors. This article is an open-access article distributed under the terms and conditions of the Creative Commons Attribution (CC BY) license (https://creativecommons.org/licenses/by/4.0/).

\section{Introduction}

Many researchers have extensively studied the impact of the electric field on the biological cell since the late 1950s. A cell is made up of three parts: cytoplasm (electrolyte) that contains the nucleus, mitochondria, and other cell organelles, plasma membrane (insulator/dielectric) that surrounds the cytoplasm to protect it, and extracellular membrane. Molecular transport into the cell occurs through the plasma membrane, which is generally (in the absence of an external electric field) non-permeant. The structural change in the cell membrane due to the application of electric pulses or dc electric fields leads to the formation of hydrophilic pores in the cell membrane. The phenomenon is called electroporation or electropermeabilization. The hydrophilic pores in the cell membrane due to electroporation act as a pathway for transporting molecules into the cell [1-3]. The transient structural changes in the cell membrane can be attained by exposing a cell to the electric pulses or electric fields [48]. The mechanism leading to electroporation is still not understood clearly $[9,10]$. However, the use of electroporation in the domains of medicine and biotechnology such as electrochemotherapy (ECT) [11], tissue ablation [12], electro-gene transfection (EGT) [13], insertion of molecules in the cell membrane, electrofusion [14], transdermal delivery of drugs [15] and food preservation [16,17] have been studied extensively. The experimental data and 
theoretical description of the electroporation are not clearly in agreement with each other. The various studies have shown that the parameters on which electroporation depends are: amplitude of electric field (E), number of pulses $(\mathrm{N})$, duration of the pulse $(\mathrm{T})$, and pulse repetition frequency (PRF) [18]. The amplitude or strength of electric field plays a crucial role in electroporation because the electroporation occurs above the threshold or critical value of the applied electric field.

The electroporation phenomenon has been used to study molecular interactions since 1999. Kotnik et al. [3] studied the behavior of a spherical cell exposed to the electric pulse to analyze the change in the permeability and conductivity of the cell membrane. The post-electric pulse behavior of the cell membrane was also studied to find the parameters affecting the stabilization of pores and the relation between transient and long-lived pores. Chiapperino et al. [19] studied electroporation by exposing cell clusters to electric pulses of high intensity. The study's objective is to assess the effects associated with cell shape variability, randomness, conductivity on electric field intensity versus pulse duration behavior. Perrone et al. [20] developed a macroscopic mathematical model to study mass transfer in electroporated cells. The author concluded that pores of different sizes are created due to local application of electrical field, and after the pulse, all the pores get shrunk in size, but the author fails to give any information about the logarithmic variation of pore density with rotation of the cell. Jayasooriya et al. [21] demonstrated a simulation of molecular transportation through an electroporated cell. The author used a 2-dimensional model of a cell placed between two electrodes with a static electric field for the numerical simulation of molecular transport. Kaushik et al. [22] demonstrated the cellular uptake of magneto-electric nanoparticles by using ac-magnetic field simulation. The author performed nano electroporation (NEP) in microglial (MG) brain cells as a target for nano-neuro-therapeutics. The author further stated that NEP technique can be adapted as an alternative technique for nanotherapeutics and nano neurosurgery, where high uptake of nanomedicine is required for effective and timely treatment of the disease.

Argus et al. [23] studied the effect of inter pulsed delay time on delivering two different sized molecules, i.e., Fluorescein-Dextran (FD) conjugates using two-pulse electroporation on 3T3 mouse fibroblast cell. The author concluded that membrane electroporation is a complex process with short-term and long-term components, which may explain the variation in membrane resealing times reported earlier.

Novickij V et al. [24] studied the electroporation in cell membrane due to high frequency $(\mathrm{MHz})$ pulse repetition frequency in place of low-frequency protocols to achieve better results. In the experiment, the authors exposed Chinese hamster ovary $(\mathrm{CHO})$ cells to 10 pulses of $200 \mathrm{~ns}$ of strength $10-14 \mathrm{kV} / \mathrm{cm}$. They reported a maximum of $0.82 \mathrm{~V}$ induced transmembrane voltage (ITMV) after the third nano-second electric pulse. The experimental data of the study confirms that continuous electric pulses induce better electroporation than the sub MHz pulse repetition frequency (PRF) regions. In vivo studies of DNA injection in the mouse's retina were studied by De Melo J. et al. [25]. The author presented in-vivo electroporation for effective and speedy insertion of DNA plasmids into neonatal mouse retina. In this method, DNA solution is injected to localized DNA between the retinal pigmented epithelium and the mouse's retina. Five square electric pulses each of 80 volts and $50 \mathrm{~ms}$ duration with $950 \mathrm{~ms}$ interval between pulses are applied using a tweezer electrode across the mouse retina for electroporation. In Naptotnik T.B. et al. [26], authors reviewed various detection methods of plasma membrane electroporation. The reviews included are the transport 
of non-permeant exogenous substances, leakage of cellular components, physical and chemical methods, total internal reflection fluorescence microscopy (TIRF), di-electrophoresis (DEP), second harmonic generation (SHG), Fourier transforms infrared spectroscopy (FTIR). In physical and chemical methods, the passive electric properties of the cell membrane are measured and used to detect electroporation.

The works on the electroporation studied so far do not explain the electroporation mechanism and the various parameters affecting it. In this paper, a theoretical model of molecular transport through a single nanopore into the spherical cell is presented to study the pulse parameters affecting the electroporation of the cell.

\section{Materials and Methods}

\subsection{Theory and calculations.}

Molecular transport through a pore during an applied pulse occurs due to diffusion and by electrophoretically driven transport. The molecular transport occurs through hydrophilic pores in the cell membrane caused by electric pulses across the cell [20,27,28]. After the electric pulse is removed, most of the pores are resealed, but it is found that some of the pores last seconds to minutes after the pulse is removed [28]. It can be concluded that most of the molecular transport occurs during an electrical pulse.

The electrical equivalent of a biological cell is an electrolyte (cytoplasm) surrounded by a dielectric medium (plasma membrane). When a cell is placed in an external electric field, the dielectric (plasma membrane) is polarized, and the voltage across it, called induced transmembrane voltage (ITMV), is set up. The cell is placed between electrodes, separated by a very small distance. The voltage is applied to cross the electrodes to set up an electric field for the plasma membrane polarization, leading to the cell's electroporation. This arrangement is known as patch-clamp configuration. The induced transmembrane voltage (ITMV) caused by this arrangement is constant over the exposed patch [29]. The Schwan steady-state equation is used to analyze ITMV in a spherical cell $[29,30]$.

The transient response of the cell is neglected because the cell membrane charging time is very short compared to the duration of the applied electric pulse. Therefore, a biological cell can be modeled as a steady-state. This condition simplifies Maxwell's equation to Laplace steady-state equation:

$\vec{\nabla} \cdot(\sigma \vec{\nabla} V(x, y, z))=0$

or $\sigma \nabla^{2} V(x, y, z)=0$

Since $\sigma$ (conductivity) $\neq 0$

Therefore, $\nabla^{2} V(x, y, z)=0$

The electric field distribution corresponding to the voltage is given by:

$\vec{E}=-\vec{\nabla} V$

Rewriting equation (1) in spherical polar coordinates, we have

$\nabla^{2} V(r, \theta, \varphi)=\frac{1}{r^{2}} \frac{d}{d r}\left[r^{2} \frac{\partial V(r, \theta, \varphi)}{\partial r}\right]+\frac{1}{\sin \theta} \frac{d}{d \theta}\left[\sin \theta \frac{\partial V(r, \theta, \varphi)}{\partial \theta}\right]+\frac{1}{\sin \theta}\left[\frac{\partial^{2} V(r, \theta, \varphi)}{\partial \varphi^{2}}\right]=0$ 
Azimuthal symmetry demands that $\mathrm{V}$ does not depend on $\varphi$, therefore, equation (3) can be written as

$\nabla^{2} V(r, \theta)=\frac{1}{r^{2}} \frac{d}{d r}\left[r^{2} \frac{\partial V(r, \theta)}{\partial r}\right]+\frac{1}{\sin \theta} \frac{d}{d \theta}\left[\sin \theta \frac{\partial V(r, \theta)}{\partial \theta}\right]=0$

or $\frac{1}{r^{2}} \frac{d}{d r}\left[r^{2} \frac{\partial V(r, \theta)}{\partial r}\right]+\frac{1}{\sin \theta} \frac{d}{d \theta}\left[\sin \theta \frac{\partial V(r, \theta)}{\partial \theta}\right]=0$

Using the variable separation method, we can write equation (4) into two equations depending on $r$ and $\theta$, respectively. The solution of these equations gives the value of ITMV given by:

$V_{m}(I T M V)=\frac{3}{2} \operatorname{Er} \cos \theta$

where variables have their usual denotations. In this simulation $V_{m}(I T M V)$ is considered to be $1 \mathrm{~V}$ as it is the minimum voltage required for a cell to be electroporated successfully.

Equation (5) is valid only if no net charges are present in any region of the cell (extracellular, cell membrane, and intracellular), and the maximal steady-state value of ITMV is then calculated [5].

The induced transmembrane voltage depends on the strength of the electric field and the radius of the cell. It is maximum at both poles of the cell. The electric field inside the cell membrane is given by $E=\frac{V_{m}}{d}$, where $\mathrm{d}$ is the thickness of the cell membrane. The strong electric field is responsible for pore formation.

To model the molecular transport through a pore in COMSOL multiphysics software, we can use either "Transport of dilute of species" or "Transport of concentrated species" depending upon the initial species concentration.

Transport of diluted physics is based on migration under the electric field and Fick's law to evaluate molecular transport. The same has been done by Jayasooryia et al. [21], and Karal et al. [31]. The equation of Fick's law is as follows

$$
R_{i}=\frac{\delta C_{i}}{\delta t}+\nabla \cdot\left(-D_{i} \cdot \nabla C_{i}-z_{i} \cdot u_{m, i} \cdot F C_{i} \cdot \nabla V\right)
$$

where $R_{i}$ is reaction rate of species, $C_{i}$ is the concentration of the molecules, $D_{i}$ is diffusion coefficient, $z_{i}$ is charge number, $u_{m, i}$ is the mobility of molecules, $\mathrm{V}$ is the electrical potential in the cell membranes (ITV) [32].

\subsection{Simulation.}

Molecular transport simulation in electroporated cells is being done with a computerbased technique to mimic the real-world process. Simulation of molecular transport is done to demonstrate the effects of electroporation. The simulations were performed in COMSOL Multiphysics software. All simulations were performed on a PC $(3.20 \mathrm{GHz}$ Intel Xenon Processor, 16 GB RAM), and each of the simulations lasted around 25-30 mins as per the nature and number of pulses being used. To demonstrate the effect of electroporation, a 2-dimensional model is constructed with two electrodes, and a spherical cell having a radius of $15 \mu \mathrm{m}$ is placed at the middle of the electrodes. The membrane of the cell is having a thickness of $5 \mathrm{~nm}$, and it consists of a pore having a $20 \mathrm{~nm}$ radius which represents the average of all the pores. The geometry of the cell was drawn in AUTOCAD software, and then it was imported into COMSOL Multiphysics software. The electrodes were drawn using the COMSOL software 
geometry tools, and then the union of geometry is formed. After the union of the geometry is formed, the entire geometry is portioned into 5 different domains, each representing a particular cell region as shown in Figures 1 and 2, respectively.

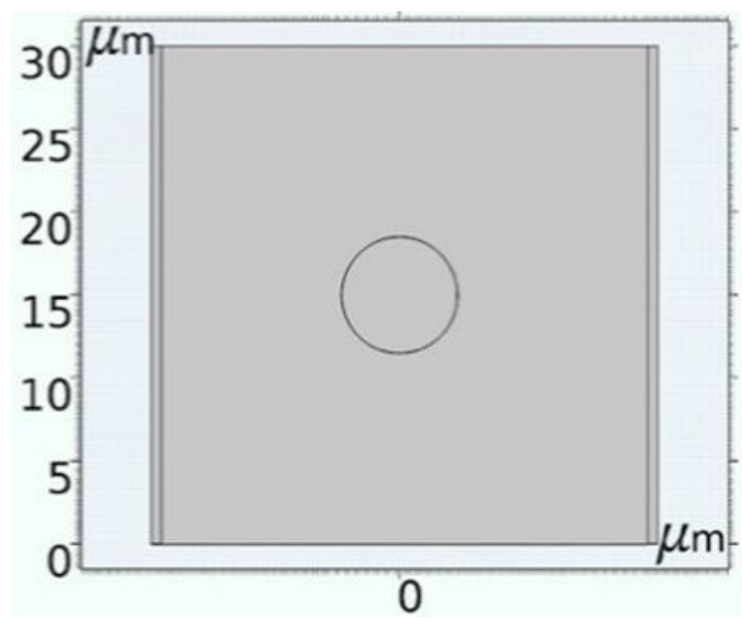

Figure 1. Geometry of the cell and electrode used in the simulation.

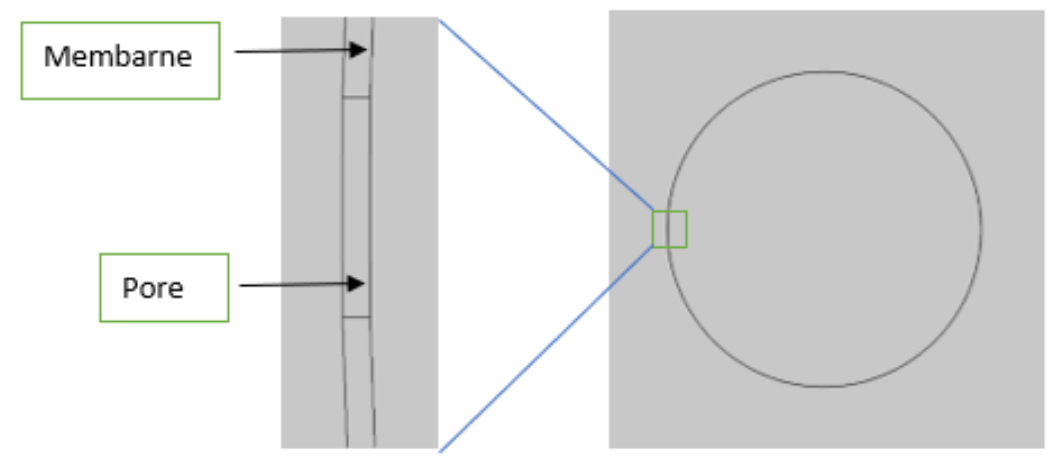

Figure 2. Zoomed view of the nanopore in the membrane.

Each domain in the geometry is assigned custom material, as in Table 1. The initial concentration of the extracellular space was fixed at $200 \mathrm{mM}$, and that of intracellular space (Cytoplasm) was fixed at 0mM.

Table 1. Material properties used in the simulation.

\begin{tabular}{l|l|c|c|c}
\multicolumn{1}{c|}{ Domain } & Material & Conductivity $\left(\mathbf{S m}^{-\mathbf{1}}\right)$ & Permittivity $\left(\mathbf{C}^{\mathbf{2}} \mathbf{N}^{-\mathbf{1}} \mathbf{m}^{-\mathbf{2}}\right)$ & Diffusion Coefficient $\left(\mathbf{m}^{-\mathbf{2}} \mathbf{s}^{-\mathbf{1}}\right)$ \\
\hline Electrodes & Gold & $43 \times 10^{6}$ & 6.9 & - \\
\hline Cytoplasm & Custom & 0.95 & 87.7 & $2.07 \times 10^{-9}$ \\
\hline Cell Membrane & Custom & $5 \times 10^{-8}$ & 16.8 & - \\
\hline Extracellular Region & Custom & 0.2 & 80 & $2.02 \times 10^{-20}$ \\
\hline Pore & Custom & 1.3 & 1 & $5 \times 10^{-14}$
\end{tabular}

In this simulation, two different types of physics are used, and both the physics results are linked together. Electric current physics is used to solve for the Vm and electric field generated. Transport of diluted species Simulation of molecular transport was done with the help of transport of diluted species(tds) physics of COMSOL Multiphysics. To model molecular transport "Migration in electric field" and "dispersion in porous media" were used as transport mechanisms. Molecular transport from the extracellular region to the intracellular region is calculated using "Migration in electric field" as an additional transport mechanism. 
The geometry has meshed with free triangular meshing for obtaining a better result. The spatial and temporal variation in the normalized electric field is calculated by using the inbuilt parameter ec.normE. The solver solves both the physics one by one in a time-dependent domain. In time-domain solver configuration, the unit of time is taken secs. The value for time is 0 to $0.3 \mathrm{~s}$, and the range is selected in steps of $0.05 \mathrm{~s}$. The value of time is changed according to the complexity of the solver configuration. Monitoring variables is done using boundary and domain probes from the "definition" tab of parameters. The concentration of the interior of the cell is being plotted with time. To further understand the molecular crowding and concentration gradient space plot of concentration is being created.

\section{Results and Discussion}

The simulation is performed using different values of the pulsed electric field (PEF). The simulation was carried out on a single spherical cell with pulses in milliseconds (10ms) and nano-seconds (10ns), in an electric field ranging from $8 \mathrm{kV} / \mathrm{cm}$ to $10 \mathrm{kV} / \mathrm{cm}$. The simulation time for molecular transport simulation is $0-0.3$ seconds. Pores of different sizes are created at the initial period due to the effect of local transmembrane potential, but when the applied pulses are removed, all of the pores shrink to small pores having an average pore size of $20 \mathrm{~nm}$. It is assumed that molecular transfer occurs from the outside of the cell to the inside of the cell after the end of the pulse to the time the pores get resealed.

Immediately after the application of pulse, ITV starts to increase. These increases in ITV result in structural changes of the membrane, which further results in an increase in membrane conductivity as per equation-5. The simulation results of molecular transport for $8 \mathrm{kV} / \mathrm{cm}$ of electric field using $10 \mathrm{~ms}$ pulses are shown in Figure 3.
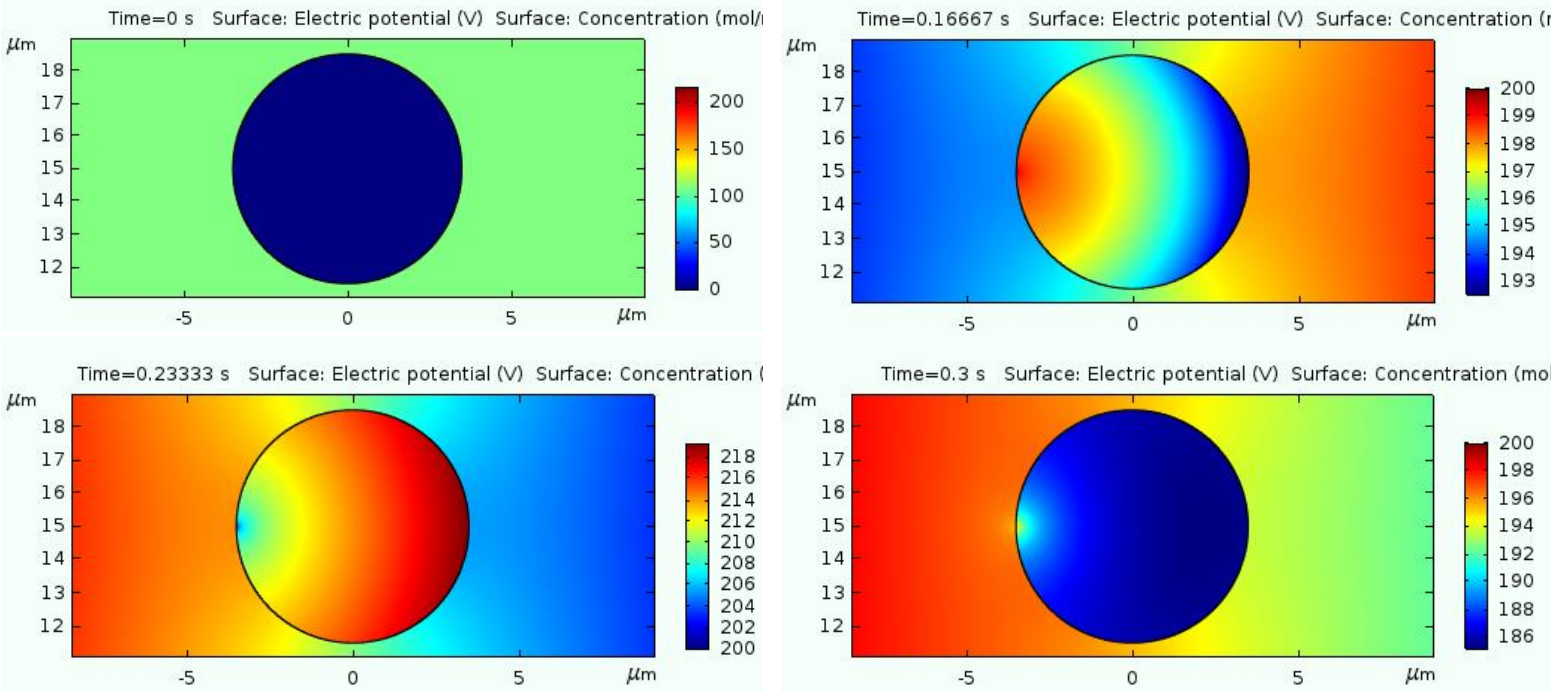

Figure 3. Intracellular concentration at $8 \mathrm{kV} / \mathrm{cm}$ using $10 \mathrm{~ms}$ pulses.

In Figure 3, it can be seen that there is a gradual increase in concentration in the initial time, and then the concentration decreases to $198 \mathrm{~mol} / \mathrm{m}^{3}$ at $0.16 \mathrm{~s}$ forming concentration bands. The concentration again increased to $216 \mathrm{~mol} / \mathrm{m}^{3}$ at $0.23 \mathrm{~s}$ and then decreased to below $200 \mathrm{~mol} / \mathrm{m}^{3}$ at the end of the simulation. This characteristic behavior is due to the creation of more pores as compared to the formation of smaller pores. The decrease in concentration is due to the closure of large-sized pores as it survives from one pulse to another.

The simulation results of molecular transport for $8 \mathrm{kV} / \mathrm{cm}$ of electric field using $10 \mathrm{~ns}$ pulses are shown in Figure 4. 

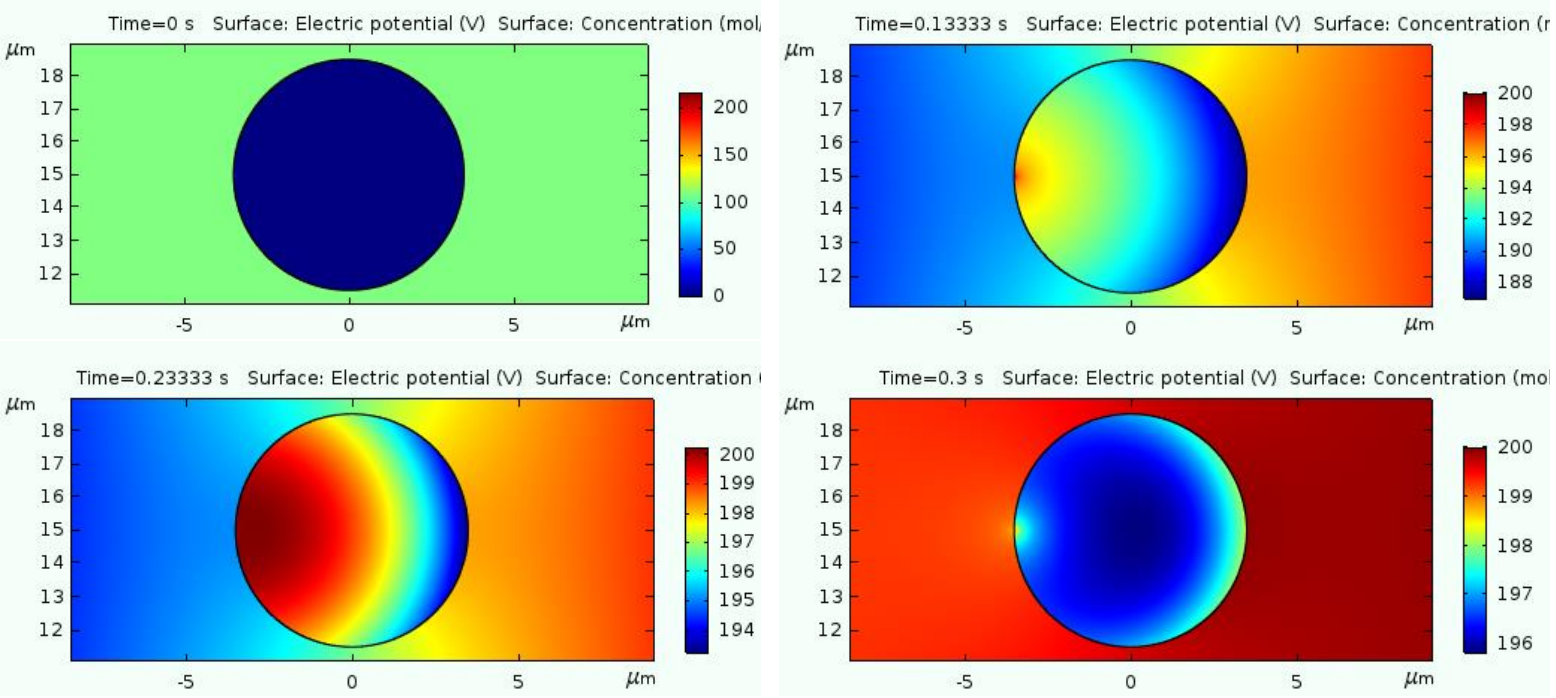

Figure 4. Intracellular concentration at $8 \mathrm{kV} / \mathrm{cm}$ using $10 \mathrm{~ns}$ pulses.

From Figure 4, it can be seen that the concentration increased in initial times, and it can also be seen that concentration bands started to form at $0.13 \mathrm{~s}, 0.16 \mathrm{~s}$, and $0.23 \mathrm{~s}$. The reason for the concentration bands can be attributed to creating a large number of small-sized membrane pores. The small-sized membrane pores also result in a decrease in the intracellular molecular concentration, as evident at $0.3 \mathrm{~s}$.

The simulation results of molecular transport for $10 \mathrm{kV} / \mathrm{cm}$ of electric field using $10 \mathrm{~ms}$ pulses are shown in Figure 5.
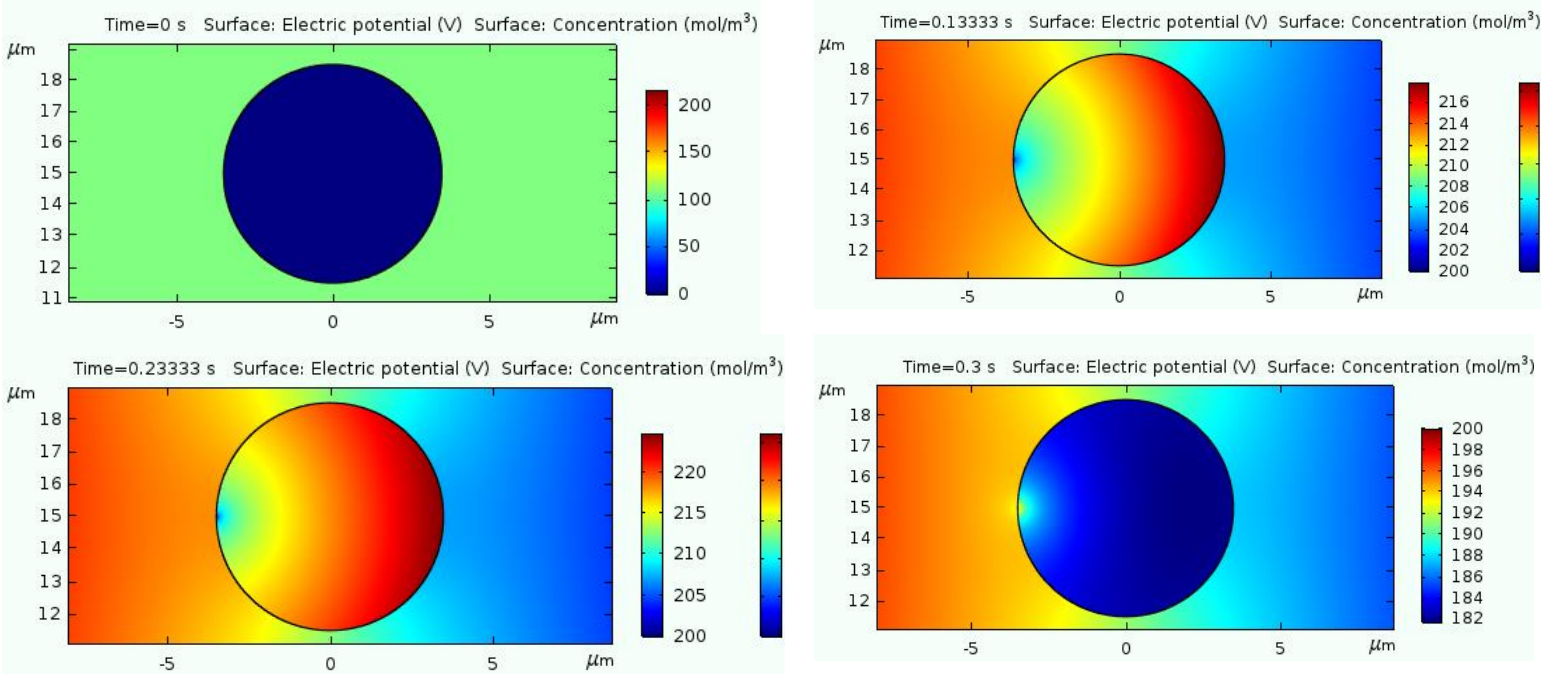

Figure 5. Intracellular concentration at $10 \mathrm{kV} / \mathrm{cm}$ using $10 \mathrm{~ms}$ pulses.

From Figure 5, it can be seen that there is a drastic change in concentration from 0s to $0.13 \mathrm{~s}$. This can be due to the application of a high electric field which creates more pores at the initial time, and thus, molecular transport is also higher in the initial time. At $0.13 \mathrm{~s}$, we can see that the concentration reached above $200 \mathrm{~mol} / \mathrm{m}^{3}$ to $216 \mathrm{~mol} / \mathrm{m}^{3}$.

The simulation results of molecular transport for $10 \mathrm{kV} / \mathrm{cm}$ of electric field using $10 \mathrm{~ns}$ pulses is as shown in Figure 6: 

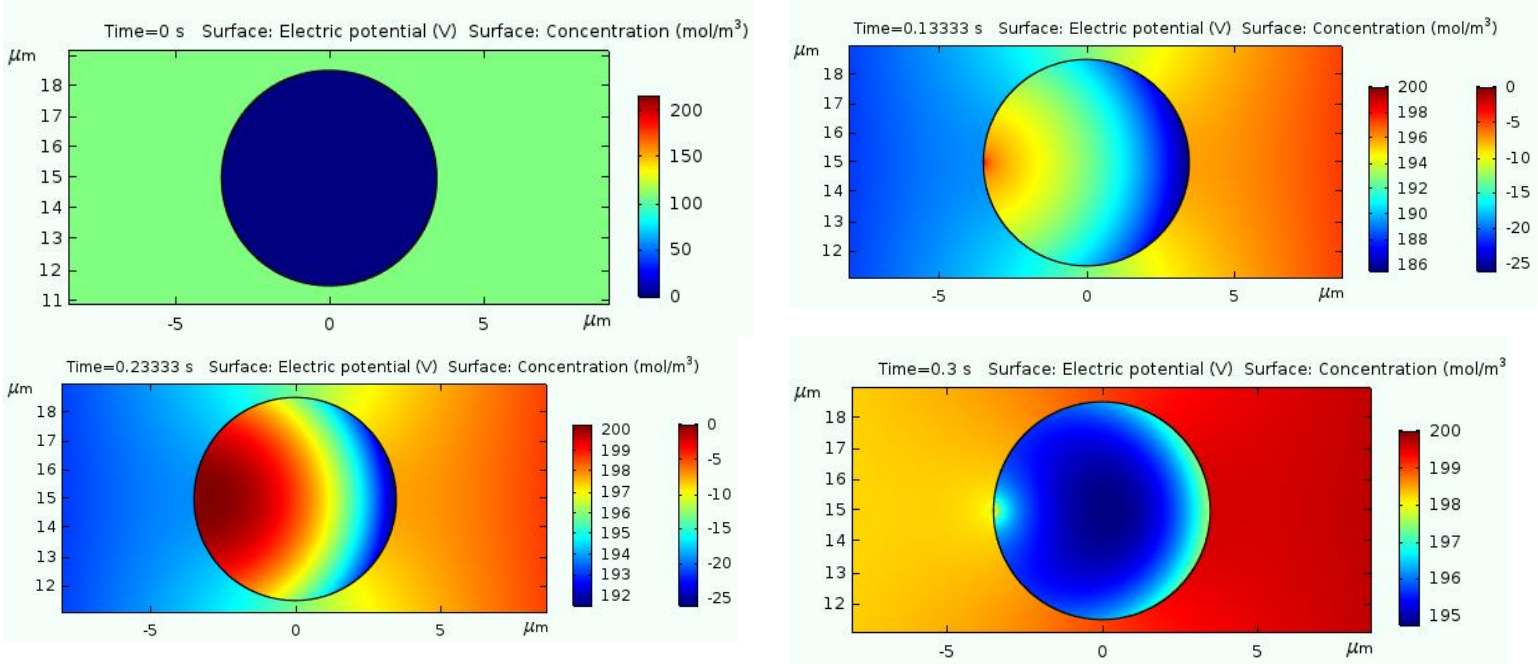

Figure 6. Intracellular concentration at $10 \mathrm{kV} / \mathrm{cm}$ using $10 \mathrm{~ns}$ pulses.

From Figure 6, it is seen that there is a drastic change in intracellular concentration in the initial period of simulation. The concentration reached $194 \mathrm{~mol} / \mathrm{m}^{3}$ after $0.06 \mathrm{~s}$. This rapid change in concentration is due to the application of a high electric field of nano-second duration. This applied electric field led to more pores in the boundary of the cell, which created banding in the concentration gradient as seen in $0.23 \mathrm{~s}$. The concentration, however, was reduced to $195 \mathrm{~mol} / \mathrm{m}^{3}$ at $0.3 \mathrm{~s}$ due to the efflux of molecules from the cell.

To better understand the simulation results, values of probes used in the simulation are exported to excel. The values of intracellular concentration for different values of electric field and pulse durations are plotted.

The plot of time vs. intracellular concentration at $8 \mathrm{kV} / \mathrm{cm}, 10 \mathrm{~ms}$ pulsed electric field is as shown in Figure 7.

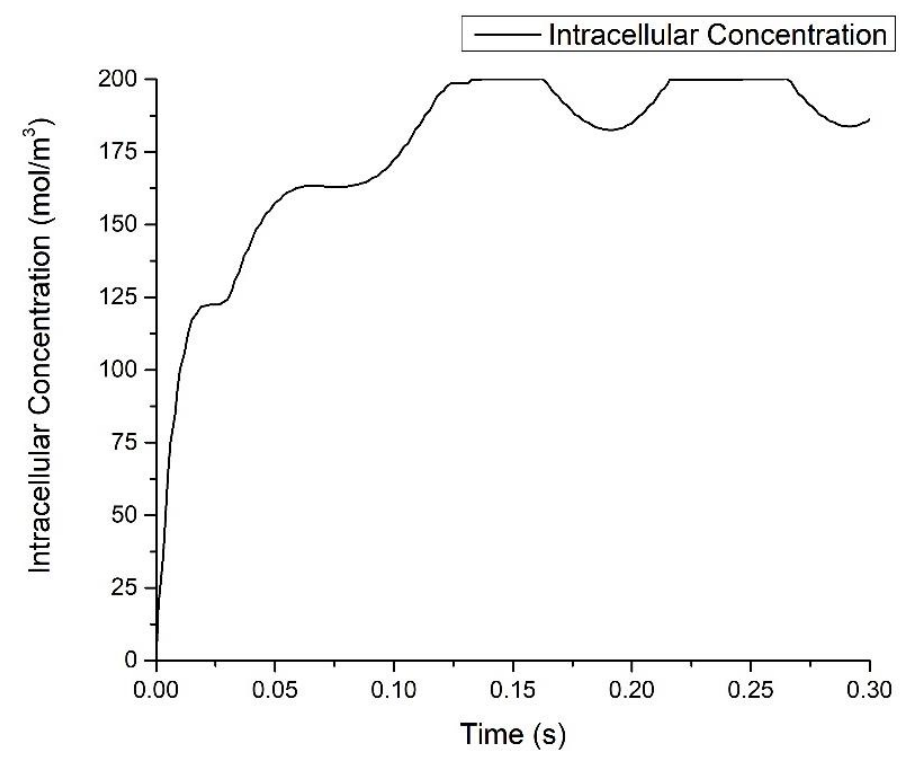

Figure 7. Time vs. intracellular concentration at $8.0 \mathrm{kV} / \mathrm{cm}, 10 \mathrm{~ms}$.

From Figure 7, it can be seen that the maximum molecular transport reached the peak value of $200 \mathrm{~mol} / \mathrm{m}^{3}$ at $0.13 \mathrm{~s}$. However, the concentration decreased in the time interval from $0.15 \mathrm{~s}$ to $0.20 \mathrm{~s}$. This characteristic behavior is due to the increased rate of formation of large pores compared to the formation of small pores with increasing large pores compared to the formation of small pores with increasing value of the applied electric field. The large-sized 
pores are created due to electric field applications, but these pores tend to decrease intracellular concentration due to the closure of the pore.

The plot of time vs. intracellular concentration at $8 \mathrm{kV} / \mathrm{cm}, 10 \mathrm{~ns}$ pulsed electric field is as shown in Figure 8.

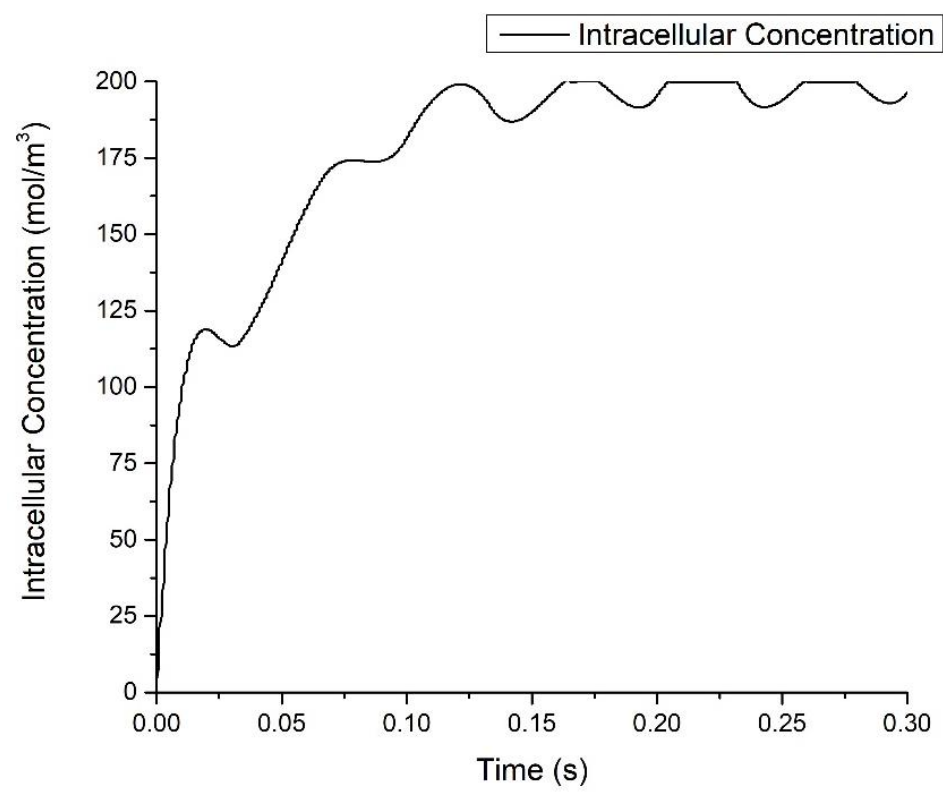

Figure 8. Time vs. intracellular concentration at $8.0 \mathrm{kV} / \mathrm{cm}, 10 \mathrm{~ns}$.

From Figure 8, it is observed that peak intracellular concentration is higher in this case, but it is observed that the intracellular concentration values fluctuate after 0.10 s and continues till the end of the simulation. The fluctuation in intracellular concentration results from applying a high nano-second pulsed electric field, which creates large populations of small membrane pores that result in the efflux of intracellular molecules and post-pulse transmembrane transport.

The plot of time vs. intracellular concentration at $10 \mathrm{kV} / \mathrm{cm}, 10 \mathrm{~ms}$ pulsed electric field is as shown in Figure 9.

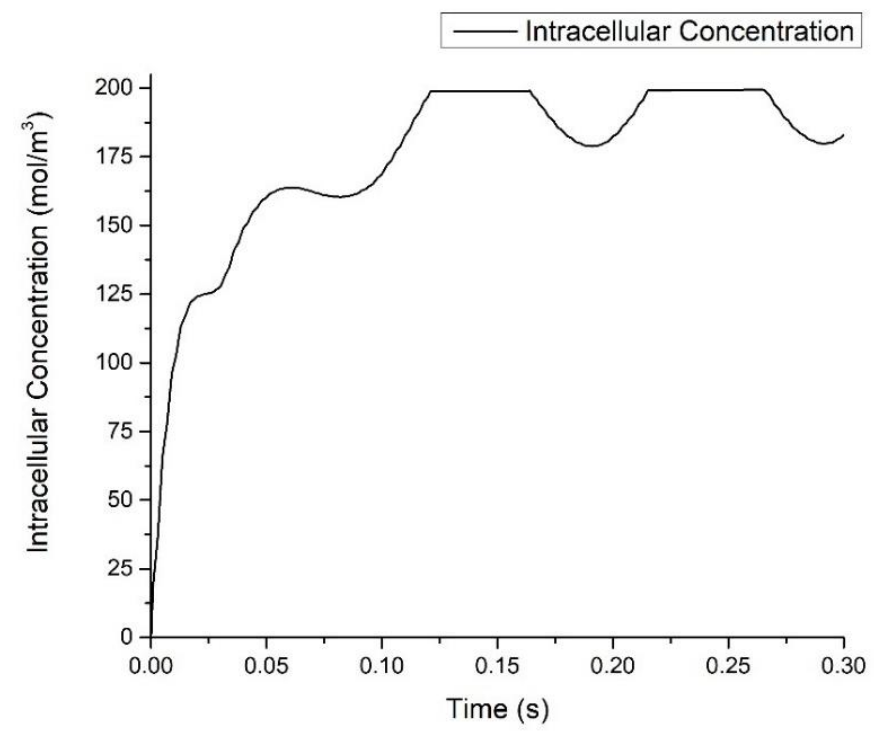

Figure 9. Time vs. intracellular concentration at $10.0 \mathrm{kV} / \mathrm{cm}, 10 \mathrm{~ms}$.

From Figure 9, it is seen that the intracellular concentration was much higher at $0.13 \mathrm{~s}$ when compared with other simulation results of millisecond pulsed electric field. From $0.15 \mathrm{~s}$ 
to $0.20 \mathrm{~s}$ the concentration decreased because of the creation and expansion of pores, resulting in molecular transport. The formation of localized concentration bands indicates this result.

The plot of time vs. intracellular concentration at $10 \mathrm{kV} / \mathrm{cm}, 10 \mathrm{~ns}$ pulsed electric field is as shown in Figure 10.

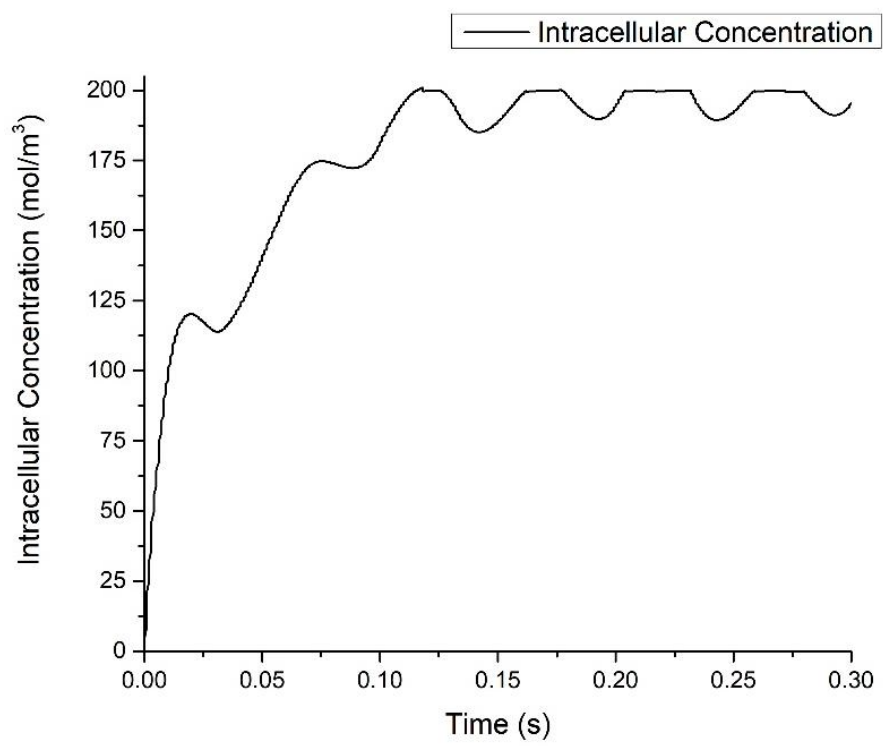

Figure 10. Time vs. intracellular concentration at $10.0 \mathrm{kV} / \mathrm{cm}, 10 \mathrm{~ns}$.

From Figure 10 it is evident that intracellular concentration using $10 \mathrm{kV} / \mathrm{cm}$ nanosecond pulsed electric field is much higher as compared with intracellular concentration using $8 \mathrm{kV} / \mathrm{cm}$ nano-second pulsed electric field. It can be concluded that nano-second pulses create enormous small-sized pores in the membrane, which results in expansion of the pore sizes as it survives from one pulse to another pulse. This increase in pore size results in the formation of a permanent pore, which results in the efflux of intracellular molecules from the cell, lowering intracellular concentration.

\section{Conclusions}

This paper presents a study of molecular transport in electroporated cellular structures. The pores are being created with the application of the electric field, and the extracellular molecules start to flow through the pores. The simulation results confirm that using a side electrode configuration results in more permeable regions, and hence molecular uptake can be studied quantitatively. Further, this study can also be conducted by taking different molecules having different sizes and concentrations such that molecular uptake can be studied in a more advanced way. A more complex cell geometry can be used for a more detailed study of the effect of nano-second pulse electroporation on the inner cell organelles and molecular uptake thereof.

\section{Funding}

This research received no external funding.

\section{Acknowledgments}

The authors would like to acknowledge the Chitkara University Research \& Innovation Network (CURIN) for offering computational facilities in their laboratory. 


\section{Conflicts of Interest}

The authors declare no conflict of interest.

\section{References}

1. Haberl Meglič, S.; Vorobiev, E.; Miklavčič, D. Editorial: Pulsed Electric Fields in Biotechnology. Front. Bioeng. Biotechnol. 2021, 9, https://doi.org/10.3389/fbioe.2021.639150.

2. Vorobiev, E.; Lebovka, N. Fundamentals of Electroporation, Theory and Mathematical Models for Simulation of PEE Processing. In Processing of Foods and Biomass Feedstocks by Pulsed Electric Energy; 2020.

3. Kotnik, T.; Rems, L.; Tarek, M.; Miklavcic, D. Membrane Electroporation and Electropermeabilization: Mechanisms and Models. Annu. Rev. Biophys. 2019, 6, 63-91.

4. Marino, M.; Luján, E.; Mocskos, E.; Marshall, G. OpenEP: an open-source simulator for electroporationbased tumor treatments. Sci. Rep. 2021, 11, 1423, https://doi.org/10.1038/s41598-020-79858-y.

5. Perera-Bel, E.; Yagüe, C.; Mercadal, B.; Ceresa, M.; Beitel-White, N.; Davalos, R. V.; Ballester, M.A.G.; Ivorra, A. EView: An electric field visualization web platform for electroporation-based therapies. Comput. Methods Programs Biomed. 2020, https://doi.org/10.1016/j.cmpb.2020.105682.

6. Sokołowska, E.; Błachnio-Zabielska, A.U. A Critical Review of Electroporation as A Plasmid Delivery System in Mouse Skeletal Muscle. Int. J. Mol. Sci. 2019, 20, 2776, https://doi.org/10.3390/ijms20112776.

7. Ghosh, D.; Gurjeet Singh, T.; Saluja, N. A critical analysis of electroporation in medical technology. Artic. Int. J. Pharm. Sci. Res. 2019, 10, 23, https://doi.org/10.13040/IJPSR.0975-8232.10(1).23-28.

8. Haldiyan, A.; Ghosh, D.; Saluja, N.; Ganeshan, S.; Thakur, G.S. Comparison of Nano-second and Millisecond Pulse Generators for Biological applications of Electroporation. Res. J. Pharm. Technol. 2021, 14, 28432851, https://doi.org/10.52711/0974-360X.2021.00501.

9. Aguilar, A.A.; Ho, M.C.; Chang, E.; Carlson, K.W.; Natarajan, A.; Marciano, T.; Bomzon, Z.; Patel, C.B. Permeabilizing Cell Membranes with Electric Fields. Cancers (Basel). 2021, 13, 2283, https://doi.org/10.3390/cancers13092283.

10. Brooks, J.; Minnick, G.; Mukherjee, P.; Jaberi, A.; Chang, L.; Espinosa, H.D.; Yang, R. High Throughput and Highly Controllable Methods for In Vitro Intracellular Delivery. Small 2020, 16, 2004917, https://doi.org/10.1002/smll.202004917.

11. Novickij, V.; Malyško, V.; Želvys, A.; Balevičiūte, A.; Zinkevičienè, A.; Novickij, J.; Girkontaite, I. Electrochemotherapy Using Doxorubicin and Nanosecond Electric Field Pulses: A Pilot in Vivo Study. Molecules 2020, 25, 4601, https://doi.org/10.3390/molecules25204601.

12. Guenther, E.; Klein, N.; Mikus, P.; Botea, F.; Pautov, M.; Lugnani, F.; Macchioro, M.; Popescu, I.; Stehling, M.K.; Rubinsky, B. Toward a clinical real time tissue ablation technology: combining electroporation and electrolysis (E2). PeerJ 2020, 8, e7985, https://doi.org/10.7717/peerj.7985.

13. Golzio, M.; Teissié, J.; Rols, M.-P. Cell synchronization effect on mammalian cell permeabilization and gene delivery by electric field. Biochim. Biophys. Acta - Biomembr. 2002, 1563, 23-28, https://doi.org/10.1016/S0005-2736(02)00369-3.

14. Geboers, B.; Scheffer, H.J.; Graybill, P.M.; Ruarus, A.H.; Nieuwenhuizen, S.; Puijk, R.S.; van den Tol, P.M.; Davalos, R.V.; Rubinsky, B.; de Gruijl, T.D.; Miklavčič, D.; Meijerink, M.R. High-Voltage Electrical Pulses in Oncology: Irreversible Electroporation, Electrochemotherapy, Gene Electrotransfer, Electrofusion, and Electroimmunotherapy. Radiology 2020, 295, 254-272, https://doi.org/10.1148/radiol.2020192190.

15. Chen, X.; Zhu, L.; Li, R.; Pang, L.; Zhu, S.; Ma, J.; Du, L.; Jin, Y. Electroporation-enhanced transdermal drug delivery: Effects of $\log \mathrm{P}, \mathrm{pKa}$, solubility and penetration time. Eur. J. Pharm. Sci. 2020, 151, 105410, https://doi.org/10.1016/j.ejps.2020.105410.

16. SKOWRON, M. Nowe technologie utrwalania żywności - badania modelowe. PRZEGLĄD ELEKTROTECHNICZNY 2020, 1, 127-130, https://doi.org/10.15199/48.2020.02.30.

17. Jin, T.Z.; Zhang, H.Q. Pulsed Electric Fields for Pasteurization: Food Safety and Shelf Life. In Food Engineering Series; 2020; 553-577.

18. Zheng, T.; Baaken, G.; Behrends, J.C.; Rühe, J. Microelectrochemical cell arrays for whole-cell currents recording through ion channel proteins based on trans-electroporation approach. Analyst 2020, https://doi.org/10.1039/c9an01737b.

19. Chiapperino, M.A.; Mescia, L.; Bia, P.; Staresinic, B.; Cemazar, M.; Novickij, V.; Tabasnikov, A.; Smith, S.; Dermol-Cerne, J.; Miklavcic, D. Experimental and Numerical Study of Electroporation Induced by Long Monopolar and Short Bipolar Pulses on Realistic 3D Irregularly Shaped Cells. IEEE Trans. Biomed. Eng. 2020, https://doi.org/10.1109/TBME.2020.2971138.

20. Perrone, A.M.; Ravegnini, G.; Miglietta, S.; Argnani, L.; Ferioli, M.; De Crescenzo, E.; Tesei, M.; Di Stanislao, M.; Girolimetti, G.; Gasparre, G.; Porcelli, A.M.; De Terlizzi, F.; Zamagni, C.; Morganti, A.G.; De Iaco, P. Electrochemotherapy in Vulvar Cancer and Cisplatin Combined with Electroporation. Systematic Review and In Vitro Studies. Cancers (Basel) 2021, 13, https://doi.org/10.3390/cancers13091993.

21. Jayasooriya, V.; Nawarathna, D. Simulation of molecular transport through an electroporated cell using https://biointerfaceresearch.com/ 
COMSOL Multiphysics. COMSOL Conf. 2017.

22. Kaushik, A.; Nikkhah-Moshaie, R.; Sinha, R.; Bhardwaj, V.; Atluri, V.; Jayant, R.D.; Yndart, A.; Kateb, B.; Pala, N.; Nair, M. Investigation of ac-magnetic field stimulated nanoelectroporation of magneto-electric nano-drug-carrier inside CNS cells. Sci. Rep. 2017, 7, 45663, https://doi.org/10.1038/srep45663.

23. Argus, F.; Boyd, B.; Becker, S.M. Electroporation of tissue and cells: A three-equation model of drug delivery. Comput. Biol. Med. 2017, https://doi.org/10.1016/j.compbiomed.2017.04.001.

24. Novickij, V.; Rembialkowska, N.; Staigvila, G.; Kulbacka, J. Effects of extracellular medium conductivity on cell response in the context of sub-microsecond range calcium electroporation. Sci. Rep. 2020, 10, 3718, https://doi.org/10.1038/s41598-020-60789-7.

25. de Melo, J.; Blackshaw, S. In vivo electroporation of developing mouse retina. In Methods in Molecular Biology; 2018, https://doi.org/10.1007/978-1-4939-7522-8_8.

26. Batista Napotnik, T.; Miklavčič, D. In vitro electroporation detection methods - An overview. Bioelectrochemistry 2018, https://doi.org/10.1016/j.bioelechem.2017.12.005.

27. Yadav, D.K.; Kumar, S.; Choi, E.H.; Kim, M.H. Electric-field-induced electroporation and permeation of reactive oxygen species across a skin membrane. J. Biomol. Struct. Dyn. 2021, https://doi.org/10.1080/07391102.2020.1730972.

28. Jarm, T.; Krmac, T.; Magjarevic, R.; Kos, B.; Cindric, H.; Miklavcic, D. Investigation of safety for electrochemotherapy and irreversible electroporation ablation therapies in patients with cardiac pacemakers. Biomed. Eng. Online 2020, 19, 85, https://doi.org/10.1186/s12938-020-00827-7.

29. Potočnik, T.; Miklavčič, D.; Maček Lebar, A. Gene transfer by electroporation with high frequency bipolar pulses in vitro. Bioelectrochemistry 2021, https://doi.org/10.1016/j.bioelechem.2021.107803.

30. Joshi, R. Simulations of Membrane Effects of Cells After Exposure to Ultrashort Pulses. Springer 2021, 77108, https://doi.org/10.1007/978-981-10-5113-5_3.

31. Karal, M.A.S.; Islam, M.K.; Mahbub, Z. Bin Study of molecular transport through a single nanopore in the membrane of a giant unilamellar vesicle using COMSOL simulation. Eur. Biophys. J. 2020, 49, 59-69, https://doi.org/10.1007/s00249-019-01412-0.

32. Kotnik, T.; Rems, L.; Tarek, M.; Miklavčič, D. Membrane Electroporation and Electropermeabilization: Mechanisms and Models. Annu. Rev. Biophys. 2019, 48, 63-91, https://doi.org/10.1146/annurev-biophys052118-115451. 